\title{
Experimental investigation into the post-filling stage of the resin infusion process
}

\author{
Q Govignon', S Bickerton' and PA Kelly
}

\begin{abstract}
The resin infusion process has developed as a low-cost method to produce large composite parts in low to medium quantities. Although the process is conceptually simple, the effects of many of the processing parameters on the postfilling stage of the process are not well understood. Most manufacturers tend to develop their approach to infusion process through trial and error, and then adhere to their 'secret recipe' without knowledge of the effect of each parameter. This paper describes an experimental investigation of the controllable process parameters and their effect on the final laminate composition, by monitoring local fluid pressure and full field laminate thickness data through the filling and post-filling stages. From the understanding of the effect of each parameter, guidelines are drawn to help manufacturers to optimise their process. The effect of using a 'brake' between the part and the vent are evaluated, and the benefits of turning the inlet into a vent at the onset of post-filling are highlighted together with methods of gaining some control on the final laminate fibre volume fraction.
\end{abstract}

\section{Keywords}

VARTM, monitoring, process control

\section{Introduction}

Resin infusion is part of the liquid composite moulding (LCM) process family. The term LCM describes the closed mould processes in which a liquid polymeric resin is impregnated through a fibrous reinforcement. Common LCM processes are resin transfer moulding (RTM), compression RTM (CRTM), RTM light and resin infusion (RI, a.k.a. VARTM). LCM processes provide good control over harmful volatile gases generated by thermoset resins, making them compliant with tougher new environmental standards established around the world. The final fibre volume fraction $\left(V_{f}\right)$ achieved can be higher and more consistent than that achieved with more traditional open mould techniques such as wet hand layup of spray moulding. LCM processes also have potential for automation, greatly reducing labour costs. ${ }^{1-3}$

Figure 1 describes the different components required for application of RI, and the different process stages. Initially, layers of fibrous reinforcement are laid on the mould to form the preform. Peel ply is then laid over the preform, allowing for easy separation of the consumables from the part, as well as providing a reasonable surface on the side of the part not in contact with the mould. Distribution media can be laid over the peel ply to enhance resin flow if the preform has low in-plane permeability. Once inlet and vent tubes are placed, the mould is closed using a vacuum bag sealed with sealant tape. With the cavity sealed, the inlet is clamped and vacuum is applied to the vents, this stage being referred to in this paper as 'pre-filling.' At the end of pre-filling, the inlet is opened and the resin penetrates the preform. During the 'filling stage,' resin pressure inside the cavity varies in position and time. From the vent to the flow front, pressure is equal to the vacuum pressure applied at the vent. Within the

\footnotetext{
'Department of Mechanical Engineering, The University of Auckland, Auckland, New Zealand

${ }^{2}$ Department of Engineering Science, The University of Auckland, Auckland, New Zealand

Corresponding author:

Q Govignon, Department of Mechanical Engineering, The University of Auckland, Auckland, New Zealand.

Email: q.govignon@auckland.ac.nz
} 

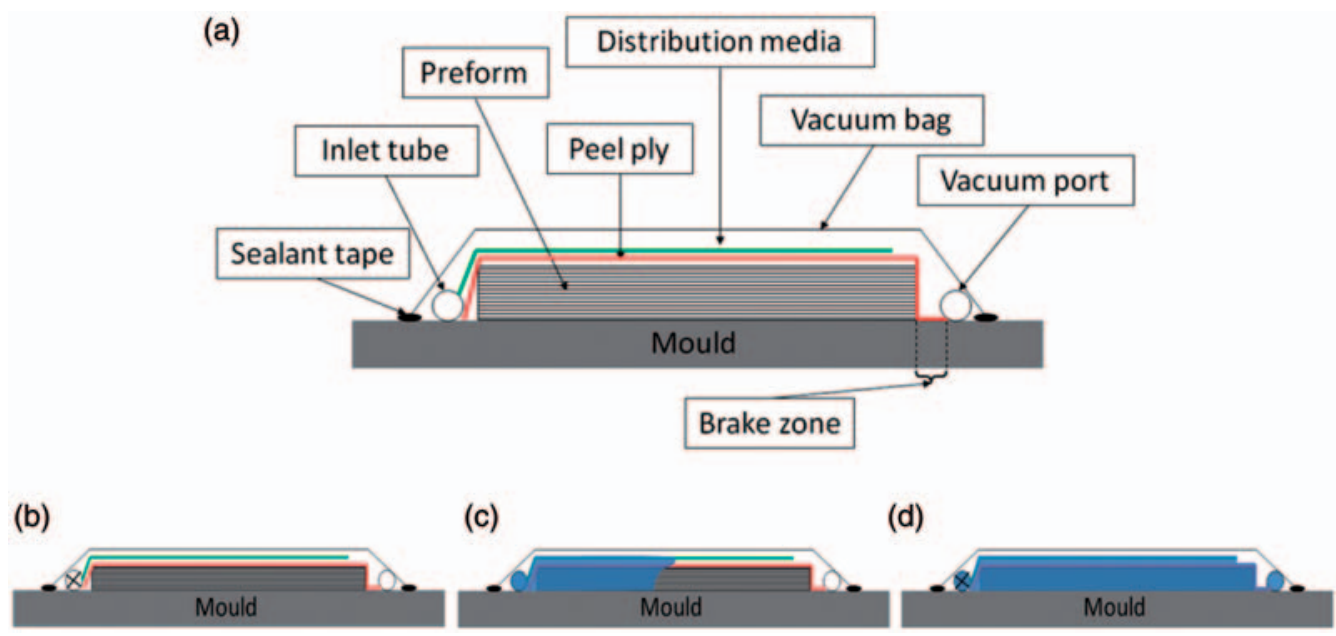

Figure I. Stages in the resin infusion process. (a) Lay up (b) Pre-filling (c) Filling (d) Post-filling.

impregnated portion of the preform, the resin pressure varies from vacuum at the flow front to near atmospheric pressure at the inlet. Once the resin front reaches the end of the preform, it is typical industry practice to clamp off the inlet; however, the inlet can also be turned into a vent. The 'post-filling' stage involves removal of excess resin, and allows resin pressure to equilibrate within the cavity. ${ }^{4-9}$ Once the resin is fully cured, the vacuum is released and the part is lifted off the mould and separated from the consumables.

As the vacuum bag employed during RI provides no flexural rigidity, the local preform thickness will vary in relation to the local resin pressure inside the cavity, as will the local permeability. ${ }^{4,7}$ Increasing resin pressure inside the cavity reduces the compaction stress on the preform, affecting local $V_{f}$ and permeability. At the end of the filling stage there can exist a significant gradient of laminate thickness and $V_{f}$ between the inlet and the vent; it is during post-filling, as the excess resin is evacuated through the vent, that the part reaches the final laminate quality.

Different techniques have been devised to improve process control and laminate quality by adding more consumables or more complexity to the equipment and process. The controlled atmospheric pressure RI (CAPRI) process ${ }^{10}$ includes a debulking phase during pre-filling, where the vacuum is applied cyclically hundreds of times in order to improve the compressibility of the reinforcement. During the filling stage the inlet is also maintained at a pressure lower than atmospheric in order to reduce the laminate thickness gradient formed during infiltration. This process results in an increased laminate quality as compared to standard RI, but at the cost of a much longer cycle time. Due to the cycling of the vacuum, the pre-filling stage is longer and the filling stage is also much longer due to the combined effect of the decreased pressure gradient and a decreased permeability caused by a higher compaction of the reinforcement. The vacuum-assisted process (VAP) ${ }^{11}$ was developed to improve the laminate quality and repeatability of the RI process. The process involves the addition of a micro porous membrane and a breather ply between the distribution media and the vacuum bag, the vent being placed on top of the breather ply. The membrane, being porous to gases but impermeable to the resin, allows for a homogeneous application of vacuum across the upper part surface. This helps to evacuate voids up through the upper surface of the laminate rather than along the length. As the vent is located on top of the membrane, no resin can bleed out of the part during post-filling, it is therefore crucial to carefully control the amount of resin injected during the filling phase in order to maintain a consistent high fibre volume fraction. The vacuum induced preform relaxation (VIPR) $)^{12,13}$ process uses a mobile vacuum chamber placed on top of the vacuum bag to locally reduce preform compaction and thus locally increase permeability. The primary goal of the VIPR process is to increase control on the progression of the flow front. However, it was found that the wet debulking accomplished by unloading and then recompacting the saturated preform enabled a higher and more consistent volume fraction to be achieved than that obtained through standard infusion, even when including a dry debulking. ${ }^{13}$

The techniques summarised in the previous paragraph provide the possibility to improve laminate quality at the cost of increased processing time, added consumable costs or added complexity, as compared to the standard RI technique. Little work has been done on the post-filling stage of standard RI. ${ }^{8,9}$ Analysis of this important stage of the process offers the possibility for simple and effective means of controlling the laminate quality of parts manufactured by 


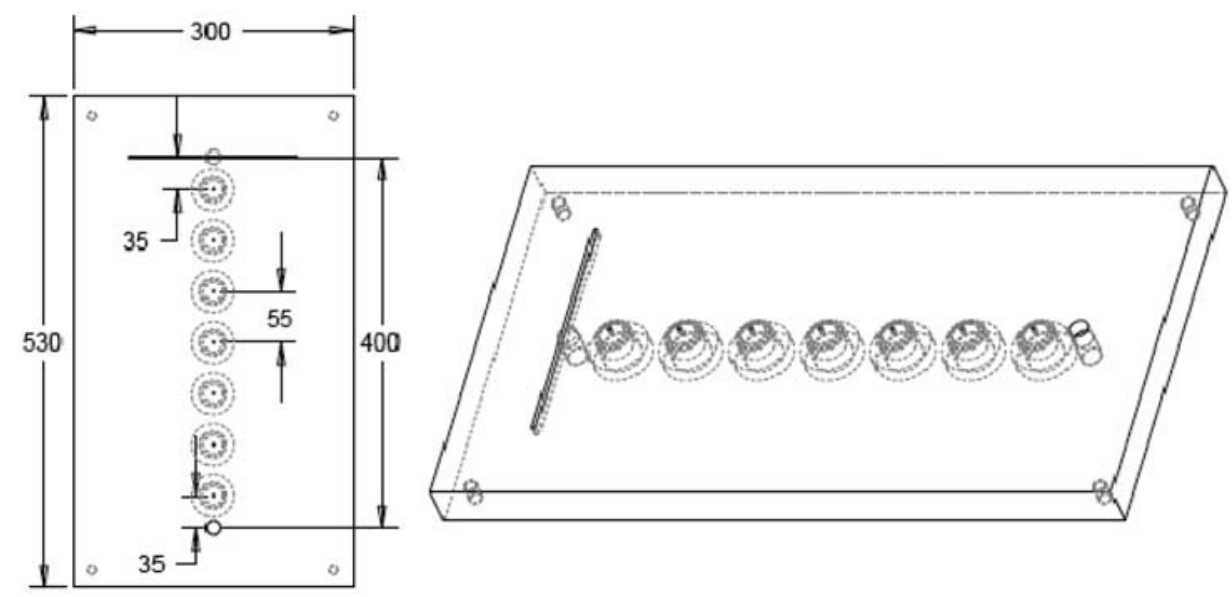

Figure 2. Scale drawings of the mould used for in this study.

RI. While a simulation tool would ultimately allow for a better control and design of the process, very little has so far been published on numerical solutions covering the post-filling stage of the process. ${ }^{14-17}$ The authors feel that it is important to experimentally determine the parameters having the most influence on the postfilling in order to include them in the development of a numerical simulation of the process. This paper presents an investigation into the potential to control the standard RI process, detailing an experimental investigation into the influence of various parameters on the post-filling stage. Modifications include changes of condition at both inlet and vent, and the inclusion of a high pressure drop brake near the vent, as is commonly applied in industry. Observations of the fluid pressure and laminate properties during filling and post-filling are presented to aid understanding of the process. In industry, the RI process is perceived as conceptually simple, ${ }^{18}$ though in practice success in moulding and the quality of the completed component are governed by subtle technical details. Through detailed experimentation and analysis, recommendations will be made to improve the robustness of the RI process for industry.

\section{Experimental facilities}

A mould and data acquisition system have been designed and built to enable detailed observation of the fluid pressure and laminate thickness during the process. The mould presented in Figure 2 was machined from a $530 \times 300 \mathrm{~mm}$ aluminium plate with a thickness of $32 \mathrm{~mm}$. It has been observed that the flexible tube and distribution media commonly used at a resin inlet ${ }^{6,7,19}$ can act as a fluid reservoir during post-filling, providing a small but non-negligible flux of fluid into the preform after the clamping of the inlet. Therefore, a non-deformable inlet system has been embedded in the mould, to enhance the repeatability and consistency of the experiments. The inlet system consists of a 180 - $\mathrm{mm}$-long slot, $3 \mathrm{~mm}$ wide and $5 \mathrm{~mm}$ deep, connected to a valve at the bottom of the mould.

Seven pressure transducer fittings were machined into the bottom of the mould. The first fitting is situated $35 \mathrm{~mm}$ from the inlet, and then the transducers are spaced $55 \mathrm{~mm}$ apart. At $35 \mathrm{~mm}$ from the seventh transducer fitting, a 10-mm diameter hole was drilled through the mould as a vacuum gate. Figure 3 presents a schematic of the data acquisition setup. Five pressure transducers, Sensortechnics 6001A4-FL, providing pressure measurements between 0 and 1 bar absolute, are mounted onto the mould and another two are used at the inlet and vent connections. The two remaining transducer fitting embedded in the mould were plugged during this study. The pressure transducers enable monitoring of local fluid pressure and, assuming Terzhagi's relation holds, ${ }^{20}$ calculation of the compaction stress applied to the reinforcement during filling and post-filling. The laminate thickness was monitored using the stereophotogrammetry system described in Reference 7, thus enabling measurements of variations in laminate properties during both filling and postfilling stages of the infusion process. A Terranova T926 gauge also monitors the pressure inside the vacuum pot, and the atmospheric pressure was measured during each experiment. As seen in Figure 3(a), weighing scale is placed under the inlet pot to measure the amount of resin injected and monitor the incoming flow rate of resin into the preform.

\section{Materials}

The reinforcement used in this study is a chopped strand mat (CSM) M705 manufactured by Owens Corning with a nominal areal weight of $450 \mathrm{~g} / \mathrm{m}^{2}$. The CSM is characterised by short randomly oriented 


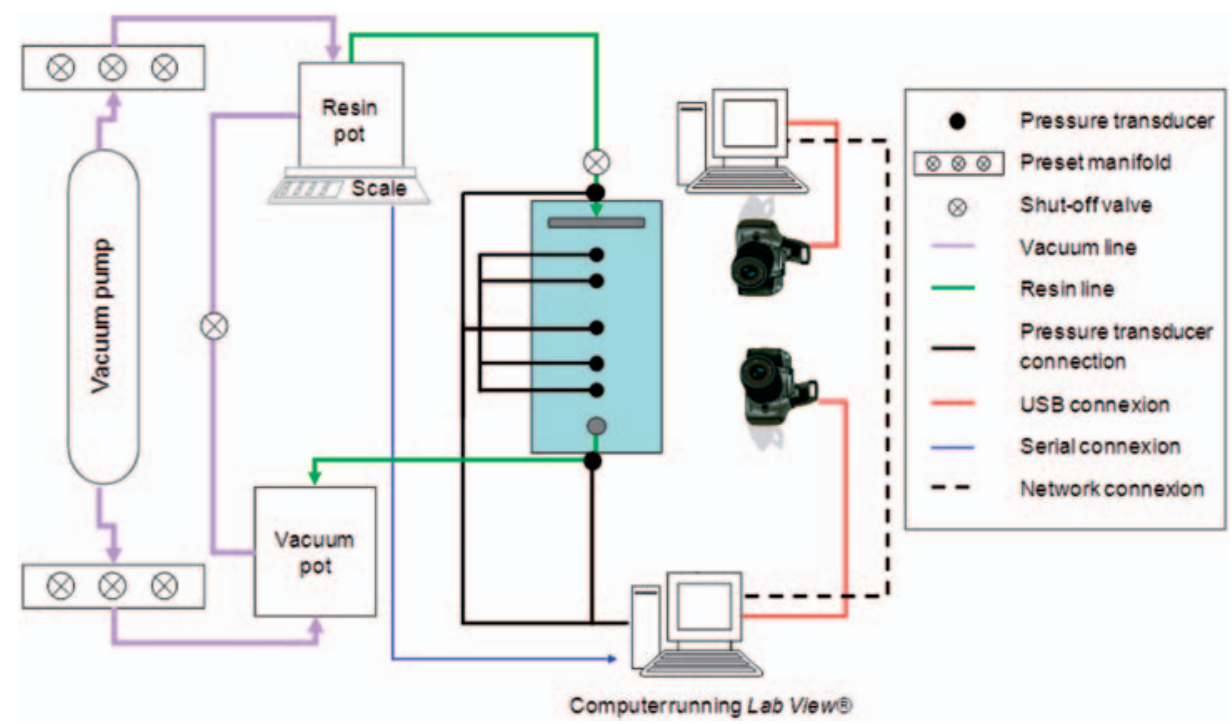

Figure 3. Schematic of the experimental setup.

bundles of fibre and a medium- to high-fibre volume fraction. This reinforcement was chosen as it provides better repeatability during processing than more structured fabrics. A woven or stitched fabric will display significant variation depending on the nesting of the tows between consecutive layers. ${ }^{21,22}$ In-plane variation of tow size and distance between the tows also affect the repeatability of manufacture using these fabrics. ${ }^{23-25}$ These effects are negligible in the CSM due to the high statistical randomness of these reinforcements. ${ }^{26}$ The effects of nesting and tow size appear on a micro scale, resulting in relatively homogeneous properties of the stack on the macro scale considered in this study. A random mat also provides an isotropic in-plane permeability enabling simpler characterisation. The compaction behaviour of the CSM reinforcement presented in Figure 4 has previously been studied in detail and modelled in References 14 and 27.

In the experiments presented in this paper, the thermoset resin was replaced by a test fluid to eliminate the variability due to the resin viscosity changing over time with cure. Mineral oil has Newtonian rheological behaviour, the dependency on temperature is easily determined using a rheometer. It has been demonstrated that a small change in fluid viscosity had little effect on the RI process, other than linearly scaling the timeframe for filling and post-filling. ${ }^{7}$ A Mobil DTE Heavy oil, with a viscosity of $0.278 \mathrm{~Pa}$.s at $20^{\circ} \mathrm{C}$, was employed in this study.

\section{Plan of experiments}

As was observed in Reference 14, changing the compaction stress on the reinforcement provides the

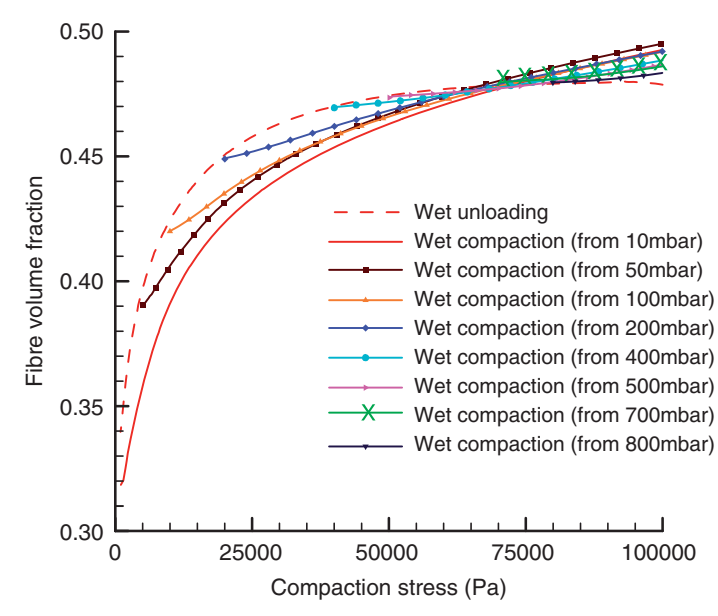

Figure 4. Experimental compaction response of the CSM reinforcement.

CSM: chopped strand mat.

possibility to control the $V_{f}$; therefore, changing the vacuum level during the post-filling stage should allow some control on the final laminate quality. The influence of different levels of post-filling pressure was therefore investigated here.

At the end of filling, the operator has two possibilities when initiating the post-filling phase by controlling either the flow or the pressure at the inlet. Traditionally, the inlet is clamped, blocking any incoming flow into the part while the excess fluid is removed through the vent and the resin pressure equilibrates along the part. Another option is to turn the inlet into an additional vent, setting local pressure to the desired post-filling pressure and allowing the excess resin to flow out of the part through both the inlet 
Table I. Plan of experiments with the variation from experiment $I$ is highlighted in bold

\begin{tabular}{lllll}
\hline Experiment \# & End of filling & Inlet during post-filling & Vent during post-filling & Brake \\
\hline I & Flow front reaches end of preform & Clamped & Full vacuum & No \\
2 & Flow front reaches end of preform & Clamped & $\mathbf{I 2 0 ~ m b a r}$ & No \\
3 & Flow front reaches end of preform & Full vacuum & Full vacuum & No \\
4 & Flow front reaches end of preform & $\mathbf{4 0 0}$ mbar & $\mathbf{4 0 0}$ mbar & No \\
5 & Flow front reaches end of preform & Clamped & Full vacuum & $\mathbf{5} \mathbf{m m}$ peel-ply \\
6 & Flow front reaches $\mathbf{3 4 0} \mathbf{m m}$ & Clamped & Full vacuum & No \\
\hline
\end{tabular}

and the vent. This technique has the potential to greatly accelerate the post-filling stage, as excess resin is concentrated near the inlet, and can be directly evacuated without being drawn through the entire preform length towards the vent. The effect of those two different options was investigated in this study.

To ensure that the preform is fully impregnated and to prevent dry spots from forming due to complex filling patterns, it is common practice in industry to use some sort of brake or sacrificial material between the vent and the edge of the preform. This material should have a high flow resistance and significantly slow the flow front when it arrives. The influence of this break zone was therefore of interest in this study.

Finally, it has been observed during previous experimental studies that a significant amount of resin is often drawn through the vent during post-filling. ${ }^{7,28}$ This means that some excess resin is being injected during the filling stage. The effect of clamping the inlet early during the filling stage was therefore investigated as a possible method to lower cost by reducing the amount of resin used in the process. By reducing the amount of resin to evacuate through the vent, this method may also provide an opportunity to reduce the post-filling time and therefore the total cycle time.

Six different scenarios have been considered, evaluating the effect of the different strategies discussed above on the post-filling stage of RI. Table 1 presents the plan of experiments. Due to the relatively long time required to prepare and perform each test, it was deemed too time consuming to perform repeats of each infusion. As the filling stage conditions were similar for all six scenarios, the filling stage data do provide information about the repeatability between experiments. Figure 5 presents a schematic of the dimensions of the preform and layup of the consumables. On the vent side, the preform was connected to the vent port via a 15-mm-long and 200-mm-wide strip of Enkachannel FPF-100 distribution tape, to provide uniform distribution of the vacuum across the width of the preform.

First, a 'standard' scenario (experiment 1) is presented in which the fluid was injected into the preform while maintaining the vacuum pressure at $470 \mathrm{~Pa}$
(4.7 millibar), the inlet being clamped as soon at the fluid reached the end of the preform. The vent pressure was maintained at the same pressure during post-filling. Experiment 2 involved increasing the pressure at the vent to $120 \mathrm{mbar}$ at the onset of post-filling with the inlet being clamped. For experiment 3, at the start of post-filling, the inlet was turned into a vent with the vacuum pressure maintained at $470 \mathrm{~Pa}$ on both sides. Experiment 4 consisted of turning the inlet into a vent but raising the vacuum pressure to $40000 \mathrm{~Pa}$ at both inlet and vent. In experiment 5, a 5-mm-wide band of peel ply acted as a break between the end of the preform and the distribution tape at the vent. The inlet was clamped at the onset of post-filling during this experiment, and the vent pressure was maintained at full vacuum $(470 \mathrm{~Pa})$. Finally in experiment 6 , the inlet was clamped once the flow front reached $340 \mathrm{~mm}$ ( $~ 90 \%$ of the preform length), and the vent was maintained at $470 \mathrm{~Pa}$ throughout the experiment.

\section{Experimental observations}

\section{Standard (experiment I)}

The stereophotogrammetry system provides full field laminate thickness measurements during filling and post-filling. Due to the design of the experiment, the flow through the laminate is purely one-dimensional; it is therefore possible to present the evolution of the laminate properties along the length of the mould in a single graph by averaging the desired property across the width of the preform. Figure 6(a) presents the evolution of thickness along the mould during the filling and post-filling stages of the standard experiment. The fill time for this and all experiments are listed in Table 2. Through the knowledge of the laminate thickness, the local $V_{f}$ can be calculated using equation (1) (with $M$ the reinforcement areal weight, $N$ the number of layers, $\rho$ the density of the fibre material and $h$ the laminate thickness). Figure 6(b) presents the evolution of the $V_{f}$. Knowledge of $V_{f}$ distribution in time can then be used to infer the resulting variation in reinforcement permeability. Figure 6(c) presents the evolution of the local reinforcement permeability calculated from the 


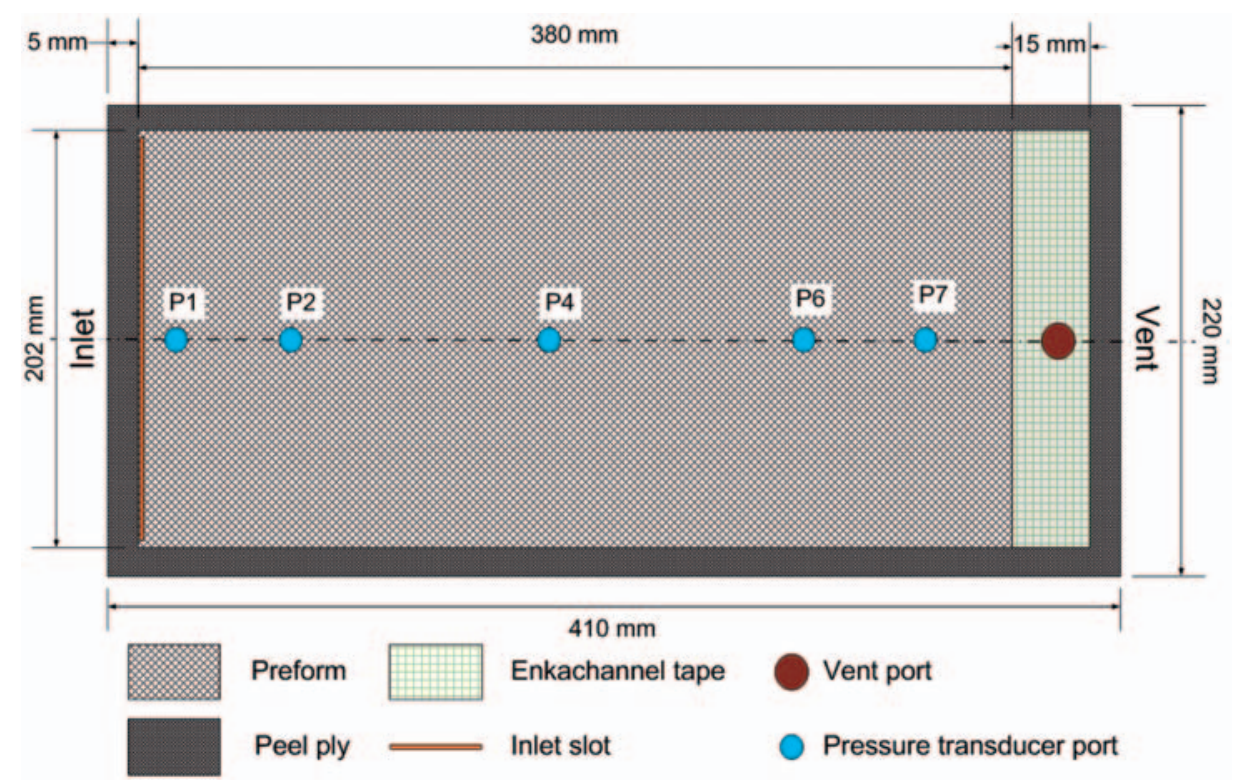

Figure 5. Schematic diagram of the part lay-up.

(a)

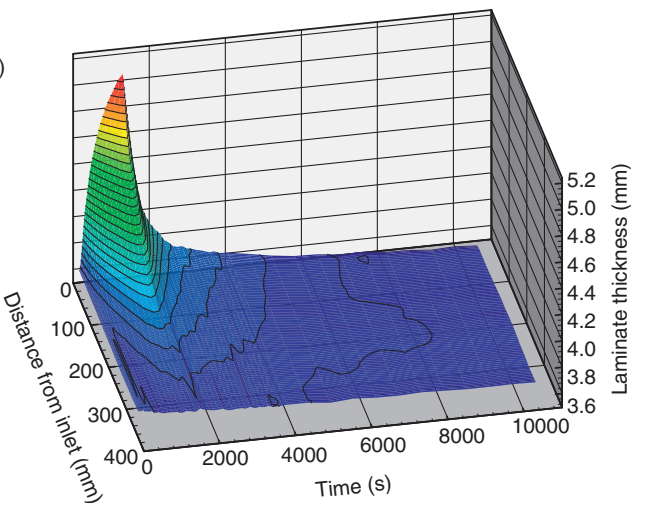

(b)

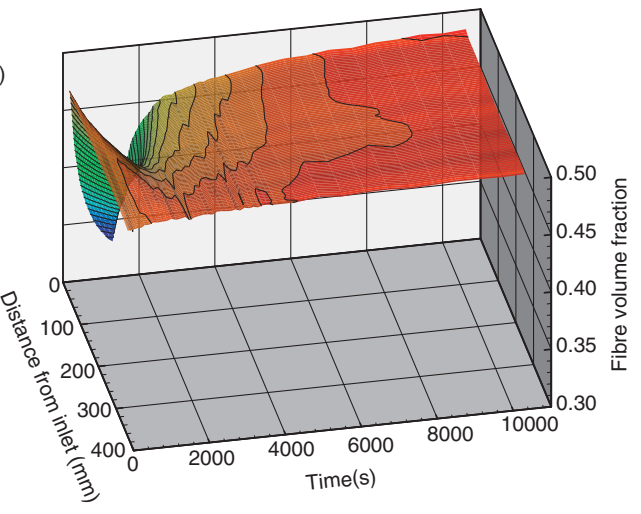

(c)

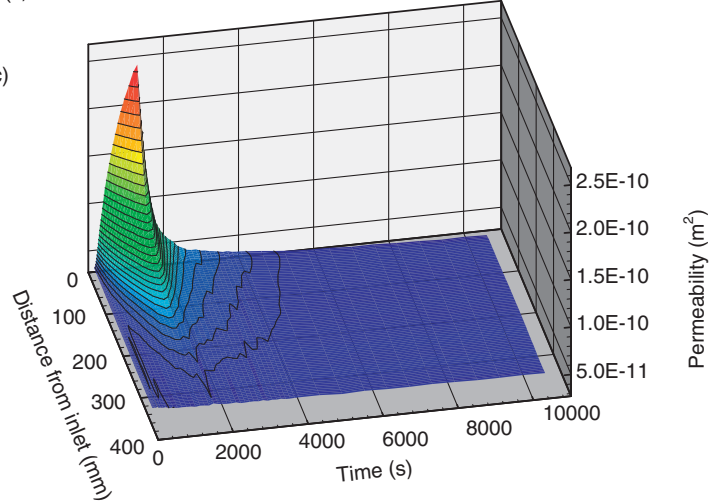

Figure 6. Evolution over time of the laminate properties along the length of the preform in the case of the standard CSM infusion: (a) laminate thickness; (b) fibre volume fraction and (c) laminate permeability. CSM: chopped strand mat. 
Table 2. Comparison of the fill time for all experiments

\begin{tabular}{|c|c|c|c|c|}
\hline $\begin{array}{l}\text { Experiment } \\
\#\end{array}$ & $\begin{array}{l}\text { Temperature } \\
\left({ }^{\circ} \mathrm{C}\right)\end{array}$ & $\begin{array}{l}\text { Approximate } \\
\text { fluid } \\
\text { viscosity } \\
\text { (Pa.s) }\end{array}$ & $\begin{array}{l}\text { Fill time } \\
\text { (s) }\end{array}$ & $\begin{array}{l}\text { Average } \\
V_{f} \text { after } \\
\text { post-filling }\end{array}$ \\
\hline I & 23 & 0.226 & 1175 & 0.493 \\
\hline 2 & 25.6 & 0.192 & 1059 & 0.486 \\
\hline 3 & 18.1 & 0.319 & 1170 & 0.478 \\
\hline 4 & 16.7 & 0.354 & 1474 & 0.462 \\
\hline 5 & 27.6 & 0.167 & 1202 & 0.476 \\
\hline 6 & 23.8 & 0.215 & $\begin{array}{l}964 \text { then } \\
|20|\end{array}$ & 0.492 \\
\hline
\end{tabular}

experimentally characterized relationship between $V_{f}$ and permeability ${ }^{7,29-31}$ presented in equation (2):

$$
\begin{gathered}
V_{f}=\frac{M \cdot N}{\rho \cdot h} \\
K=2.5 \cdot 10^{-8} e^{-12.55 \cdot V_{f}}
\end{gathered}
$$

Figure 6 clearly shows that most of the thickness and $V_{f}$ changes occur in the inlet half of the mould. On completion of filling, thickness near the inlet reduces relatively quickly. As post-filling progresses, the rate of reduction falls. From Figure 6(c), it can be seen that there is a rather large variation of permeability within the half of the preform closest to the inlet. At the end of filling, permeability is five times larger at the inlet than at the vent, and the first third of the preform has a permeability more than double that at the flow front. Throughout filling, there is a significant permeability increase on the first third of the saturated portion of the preform.

Figure 7 presents measured fluid pressure traces and the laminate thickness at the location of the transducers during the filling and post-filling stage of the standard infusion. It is observed that the fluid pressure inside the laminate takes over 10 times the fill time to stabilise during post-filling. After an initial sharp drop of pressure during a time equivalent to the fill time, the rate of pressure decay reduces considerably. It can also be noted that after $30000 \mathrm{~s}$, while the fluid pressure seems stable, a small pressure gradient remains along the laminate. The laminate thickness evolves in a similar manner, with a sharp decrease at the onset of postfilling and then a drop in the rate of thickness change. It can also be noted that while the pressure at the inlet always remains higher than at the vent, the thickness gradient in the laminate changes during post-filling; the
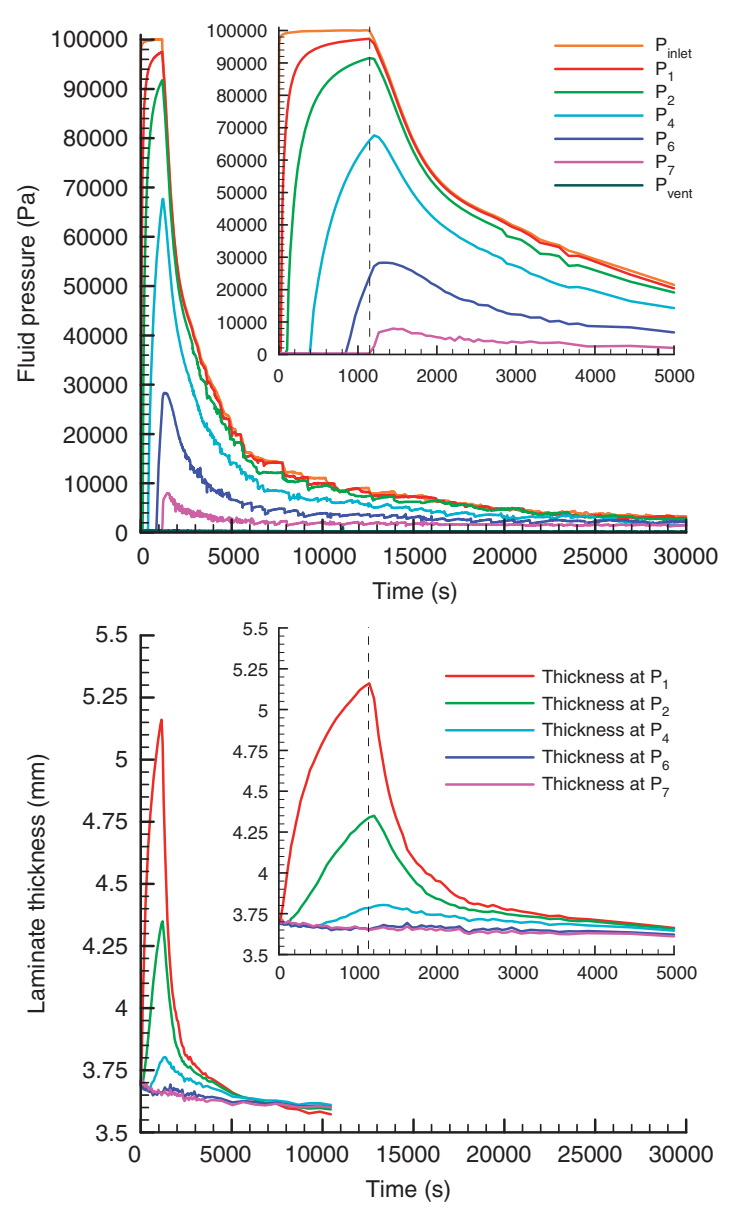

Figure 7. Fluid pressure and laminate thickness traces for the standard RI experiments (experiment I).

RI: resin infusion.

thickness at the inlet drops lower than that at the vent towards the end of the experiment. This phenomenon can be explained by the difference in reinforcement compaction history along the preform, through the filling and post-filling stages. At the inlet, the preform is submitted to a cycle of unloading and re-compaction, while close to the vent the preform is kept under one atmosphere of compaction throughout. To better demonstrate these observations, the pressure and thickness distributions at various times during the process are presented in Figure 8. The increased fluid pressure and laminate thickness within the inlet side of the preform, as compared to its end of post-filling state, clearly indicate that some excess fluid is present there during filling. This motivates the removal of excess resin through the inlet by turning it into a vent, or decreasing the amount of wasted resin by clamping the inlet early.

To compare the different infusion strategies, Figure 9 presents the evolution of the fluid pressure at each transducer for the six different infusion strategies experiments. To remove the influence of variation in 

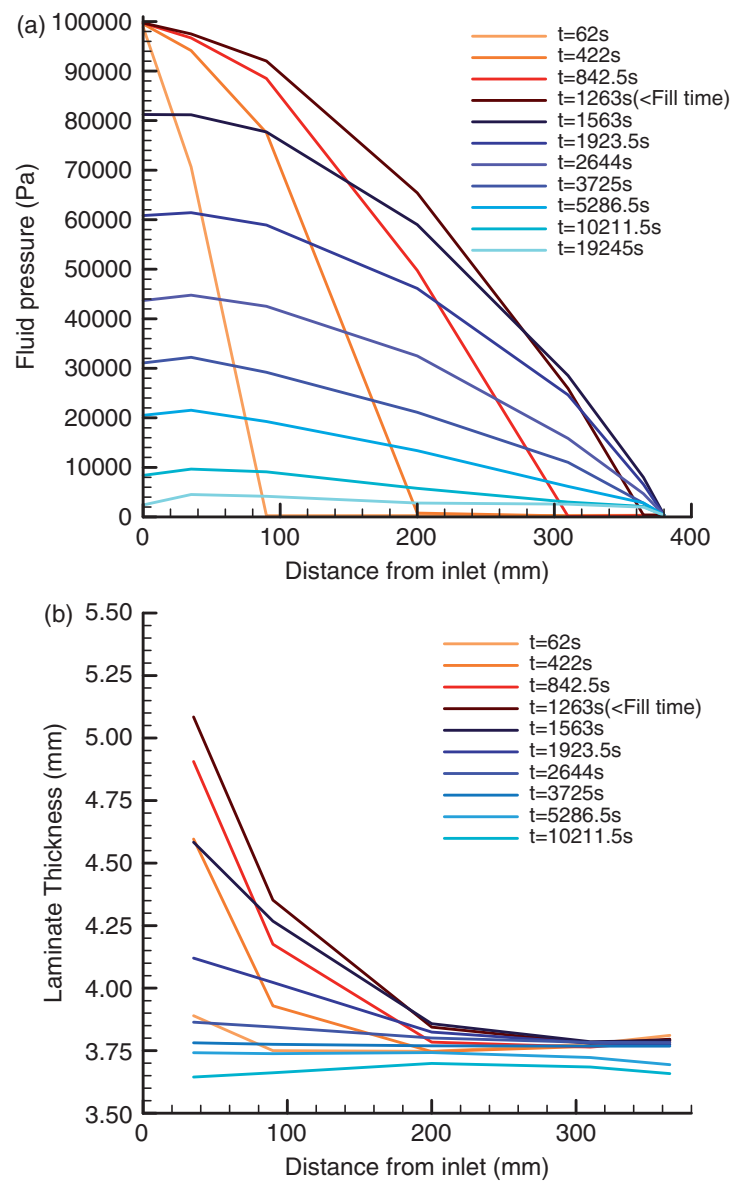

Figure 8. Pressure (a) and thickness (b) distributions at various instances during experiment $\mathrm{I}$.

filling time, the time scale has been non-dimensionalised relative to the fill time. Figure 10 presents in the same manner the evolution of the laminate thickness at the location of the pressure transducers. Table 2 presents the fill time for each experiment as well as the temperature at which the experiment was performed, the calculated fluid viscosity at that temperature and the fibre volume fraction achieved after post-filling.

\section{Change of post-filling pressure to $12000 \mathrm{~Pa}$ (experiment 2)}

From Figures 9 and 10 it can be observed that reducing to a small extent the vacuum level during post-filling does not affect the speed at which fluid pressure and laminate thickness change. Figure 11 presents the fluid pressure and laminate thickness profiles at various instances during this experiment. The final average laminate thickness and fibre volume fraction are very similar to values for experiment 1 . This makes sense when considering compaction behaviour of the reinforcement, which shows very little difference in compaction between 88,000 and $100,000 \mathrm{~Pa}^{30}$
However, there appears to be a smaller thickness gradient along the part between the inlet and vent.

\section{Inlet and vent at full vacuum during post-filling (experiment 3)}

Figure 12(a) presents the evolution of the fluid pressure during the standard experiment as well as the two experiments where the inlet was turned into a vent. Similarly Figure 12(b) presents the evolution of the thickness at these same locations for those experiments. It is observed that the pressures and thicknesses equilibrate much faster when the inlet is turned into a vent than in the standard experiment. While clamping the inlet resulted in a post-filling period equivalent to 10 times the fill time before the fluid pressure stabilised, turning the inlet into a vent reduced 10 -fold the necessary post-filling time. Figure 13 presents, in the same manner as Figure 8, the pressure and laminate thickness distribution during experiment 3. Figure 13(b) demonstrates that the thickness gradient at the end of post-filling is much more pronounced in this experiment as compared to the standard infusion. In this experiment once the pressure and thickness reached equilibrium, the final $V_{f}$ ranged from $49.3 \%$ at the inlet to $47.2 \%$ at the vent. In the light of the compaction behaviour of the CSM presented in Figure 4, ${ }^{14,27}$ the lower residual pressure at the inlet does not in itself explain the increased thickness gradient. It could be argued that the fluid flow can act as a lubricating agent. Increasing the flow at the inlet during post-filling would therefore result in increased compaction, while at the same time the flow being brought effectively to a halt near the vent side would prevent further reorganisation of the fibre tows and compaction of the reinforcement during post-filling.

It should be noted that the CSM reinforcement used for experiments 3 and 4 came from the same supplier as that used in the other experiments and characterisation tests but was taken from a different roll purchased at a later date. Small differences in the fill time (see Table 2) and laminate thickness and thickness variations can be attributed to slight variations in the reinforcement composition; the amount of binder or even the composition of the binder may have varied. However, the form of the pressure traces appears to be consistent and general observations can be made across the range of experiments.

\section{Inlet and vent at 400 mbar during post-filling (experiment 4)}

As was the case for experiment 3 , turning the inlet into a vent greatly reduced the time necessary for the fluid pressure to equilibrate during post-filling. Considering 

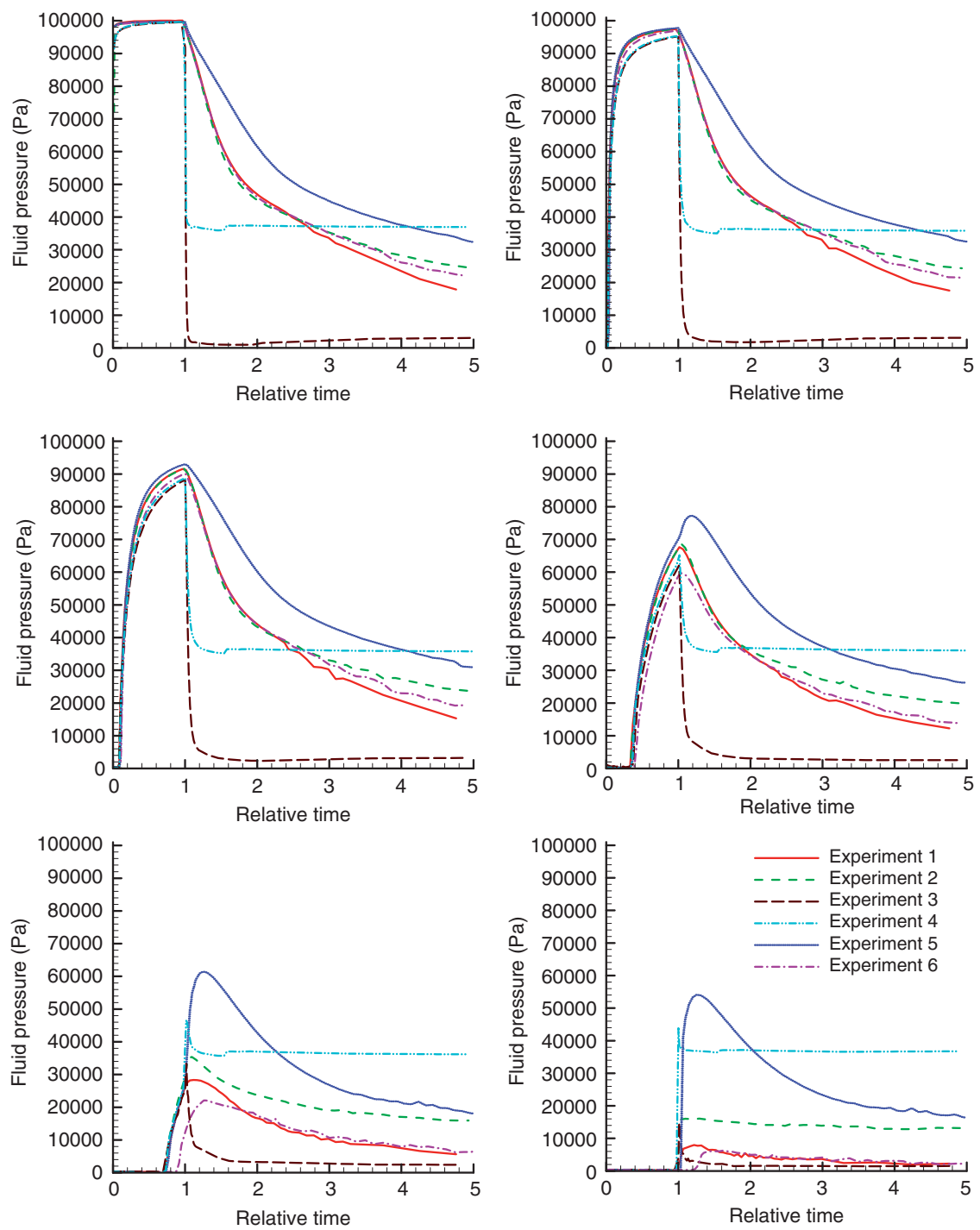

Figure 9. Comparison of the pressure traces for the six different infusion procedures with CSM reinforcement. CSM: chopped strand mat.

Figure 12 after a post-filling period slightly shorter than the fill time, the pressure and thickness gradient are very small. The fibre volume fraction, measured to be an average of $46.2 \%$, was lower than that measured when full vacuum was applied (whether at both inlet and vent or just at the vent) as the compaction stress on the reinforcement was reduced. The thickness gradient at the end of post-filling (as seen in Figure 14(b)) was found to be below the level of accuracy of the measurement technique, revealing a more consistent $V_{f}$ along the length of the part.

\section{Use of a brake (experiment 5)}

Considering Figures 9 and10, it can be observed that the fluid pressure and laminate thickness towards the vent side of the preform rise very quickly once the flow front starts to impregnate the brake zone. The pressure profile within the laminate quickly reaches a stable shape, with relatively small pressure gradients along the part. Fluid pressure then slowly decreases uniformly along the whole preform; the difference of pressure stays relatively constant between the inlet end and the break end of the preform, the rate of pressure decrease being governed by the rate at which the fluid is able to flow through the peel ply. The brake acts to slow down the pressure decay in the preform, and also helps to quickly reduce fluid pressure and laminate thickness gradients along the part. After a post-filling period equivalent to five times the fill time, laminate thicknesses are slightly higher than during the standard experiment due to lower compaction stresses applied 

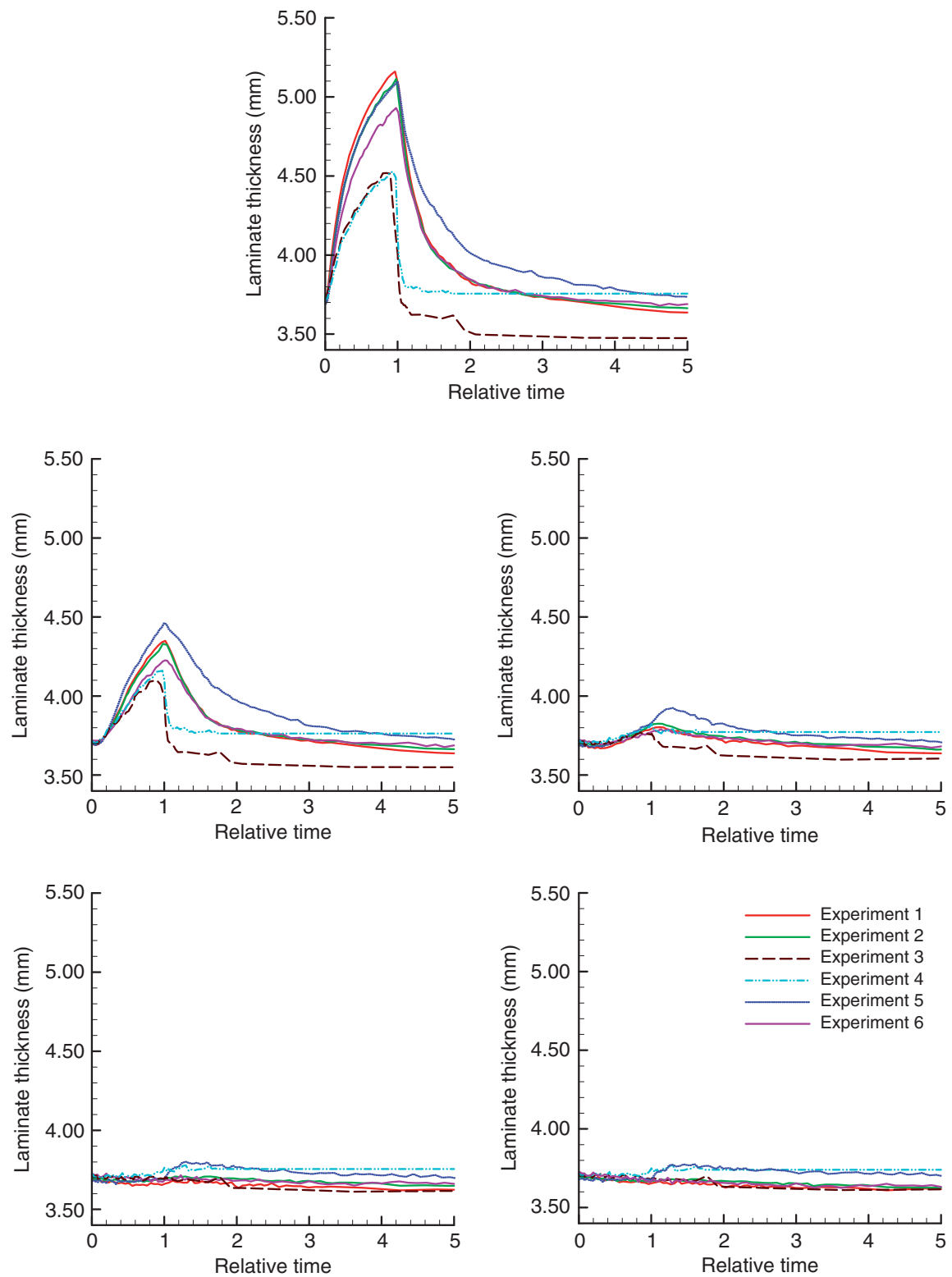

Figure 10. Comparison of the thickness traces for the six different infusion procedures with CSM reinforcement. CSM: chopped strand mat.

to the preform, and is more uniform along the length as demonstrated by Figure 15. As the majority of the preform experiences high fluid pressure during filling, a similar compaction history is applied at each position along the part. In comparison to the standard infusion, for which quite different compaction histories are experienced near the inlet and vent, this results in a more uniform part thickness.

\section{Clamping early (experiment 6)}

In this case, the inlet was clamped once the flow front had progressed $340 \mathrm{~mm}$ (preform $\sim 89.5 \%$ filled).
The excess fluid present in the saturated part of the laminate was used to fill the remaining $10.5 \%$ of the preform length. It can be noted from Table 2 that the time required to fill the entire preform was not affected. The post-filling stage also did not appear significantly influenced, the pressures and thicknesses taking the same amount of time to reach equilibrium as during the standard experiment. However, clamping the inlet early resulted in an $8 \%$ reduction in the mass of injected fluid, as measured using the weighing scales. The peak pressures and laminate thickness at the location of each pressure transducers are also reduced, due to the fact that the inlet was clamped earlier. 

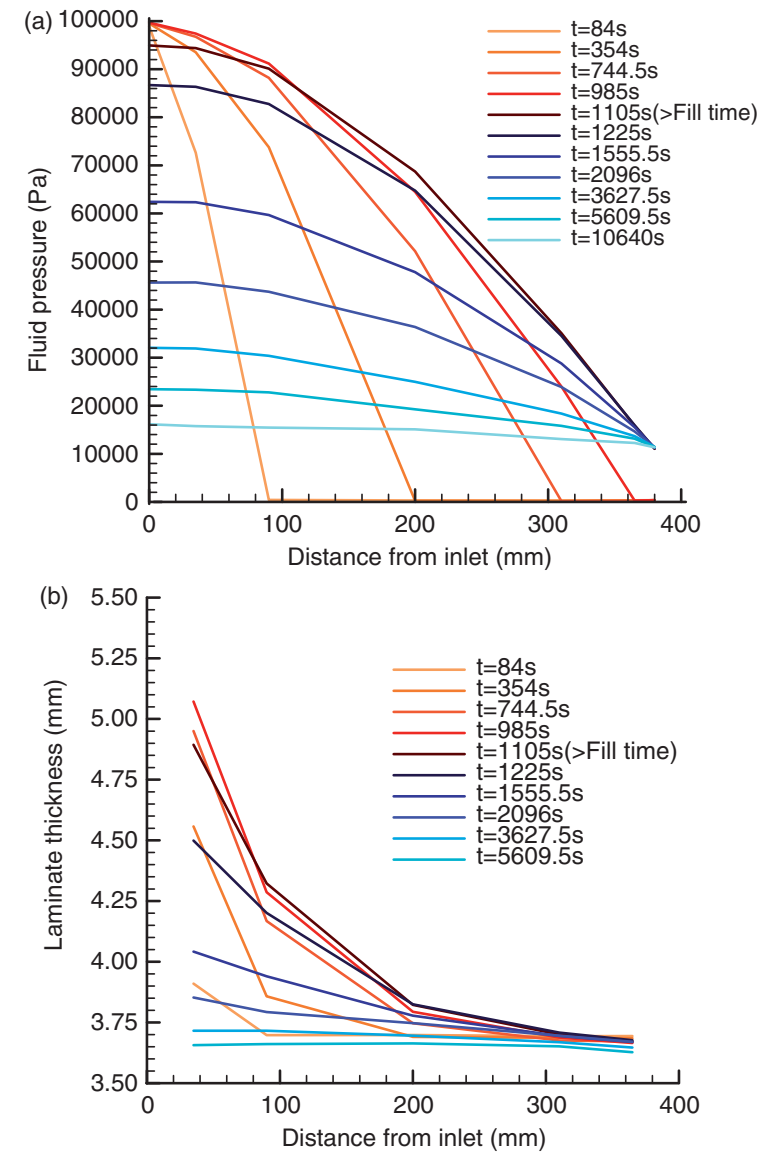

Figure II. Pressure (a) and thickness (b) profiles at various instances during experiment 2 , where the post filling pressure at the vent was raised to 120 mbar.

\section{Discussion}

It has been demonstrated that when the inlet port is simply clamped at the end of filling, a very long postfilling period is required for the fluid pressure and laminate thickness to reach equilibrium. A period 10 times longer than the fill time is required for the materials and part geometry considered here. The length of the post-filling period should be taken into consideration when choosing the resin system and tailoring its gel time. If the resin gels too early after filling, a significant thickness gradient will remain in the finished part. $^{5,8}$ Turning the inlet into a vent at the onset of post-filling demonstrates great potential for reducing the time necessary for post-filling, allowing for selection of a faster curing resin system, and therefore increased productivity.

Changing the vent pressure during post-filling decreased the thickness gradient in the final part and can also be used to decrease the compaction on the reinforcement and therefore decrease the final $V_{f}$ as in experiment 4 . The potential for controlling the final $V_{f}$, through control of the vent pressures during
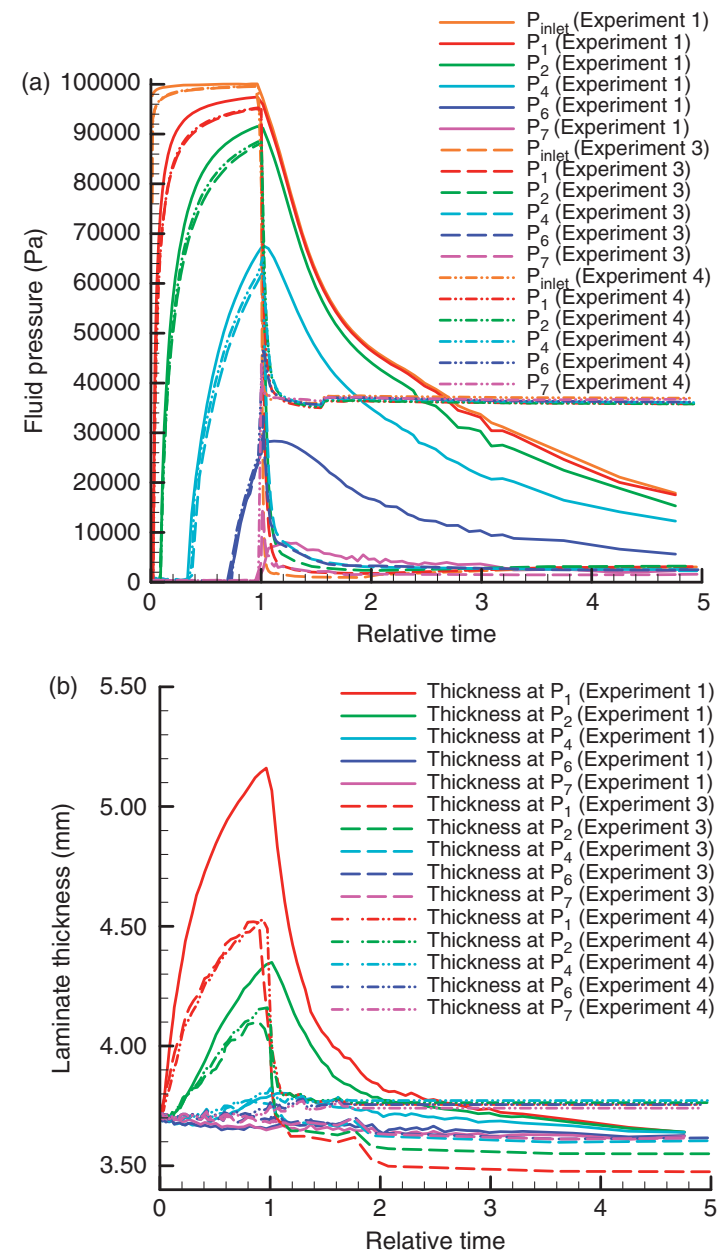

Figure 12. Comparison of the fluid pressure (a) and laminate thickness (b) traces for the standard experiment and the experiments where the inlet was turned into a vent.

post-filling, requires knowledge of the compaction behaviour of the reinforcement. Careful characterisation of the reinforcement should therefore be performed to be able to choose the right post-filling pressure to achieve the desired $V_{f}$. The resin systems commonly used for the RI process often exhibit boil off when low local resin pressure is reached, resulting in increased void content in the finished part. Some of this boil off is caused by gasses dissolved in the resin and can be reduced by properly degassing the resin before filling. Another potential cause of boil off is due to the release of water molecules during cure of the resin. ${ }^{32-34}$ Increasing vent pressure during post-filling increases the minimum resin pressure experienced throughout the laminate, significantly reducing void generation due to moisture boil off. It has been observed that if voids are entrapped in the laminate during impregnation, the size of the voids will decrease as the resin pressure increases, which will serve to increase part quality ${ }^{34,35}$ Experiment 2 has demonstrated that a small 

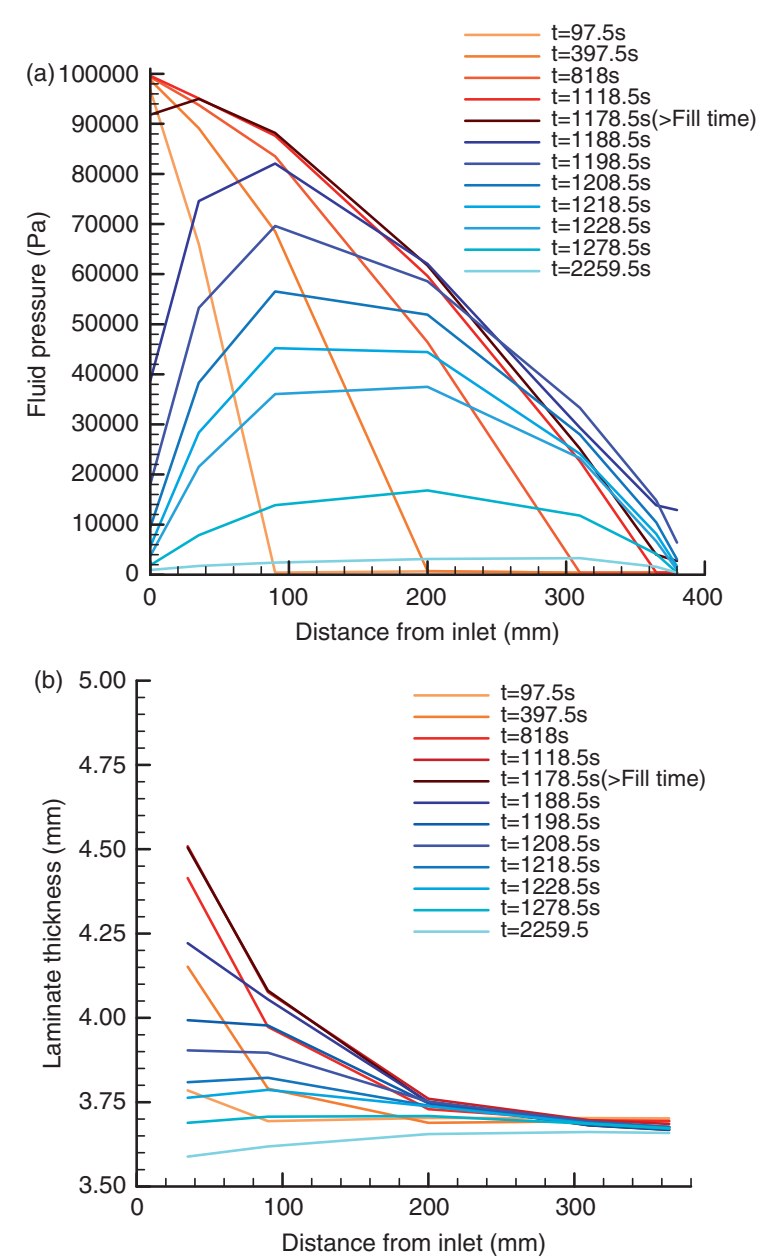

Figure 13. Pressure (a) and thickness (b) profiles at various instances during experiment 3 , where full vacuum was applied at both inlet and vent during post-filling.

increase of pressure during post-filling, while limiting the potential for resin boil off, should not significantly affect the final $V_{f}$. of the laminate. However, care should be taken when decreasing vent vacuum levels at the end of post-filling, so as not to reverse resin flow and introduce porosity through the vent. It is advisable to ensure some resin enters the vent port before changing the pressure at this location.

The use of a brake material at the vent serves to quickly reduce the pressure gradient along the laminate, by restricting the flow of fluid out of the preform. The fluid pressure near the vent increases rapidly when the resin front hits the brake material, the difference in applied compaction stress along the laminate is therefore greatly reduced, resulting in much smaller thickness gradients in the finished part. However, the laminate thickness continues to evolve slowly with time, and the final part thickness is difficult to control and is sensitive to a variety of sources of variability. The ability to choose the permeability, porosity and
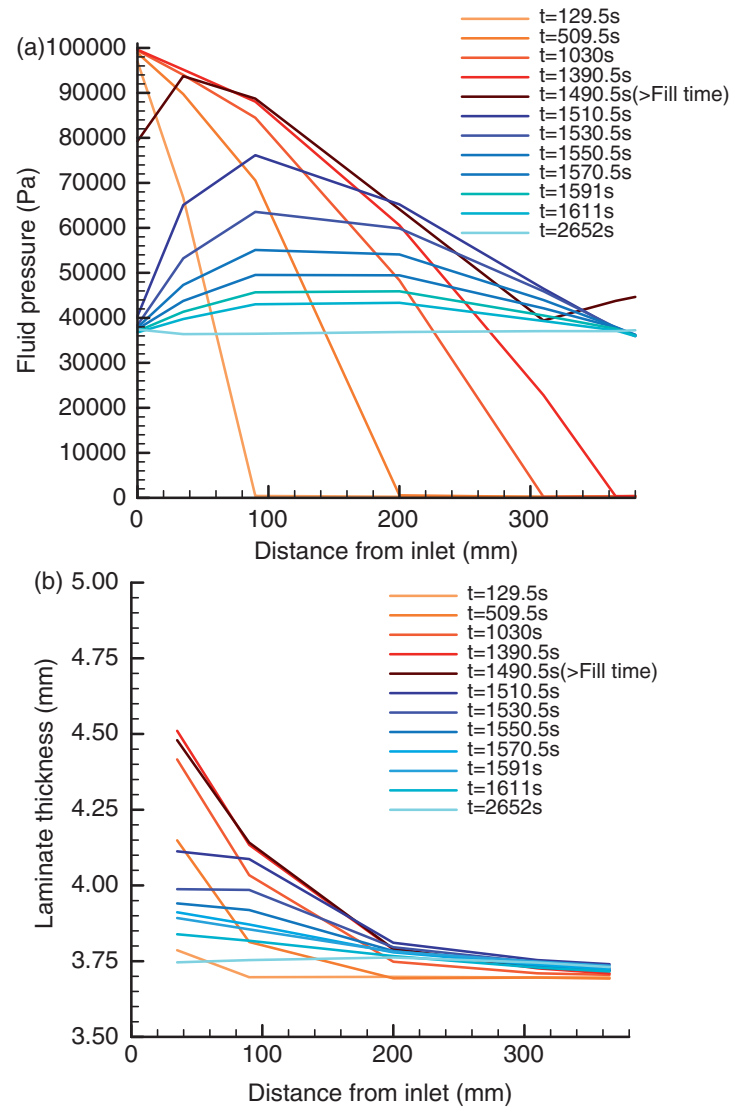

Figure 14. Pressure (a) and thickness (b) profiles at various instances during experiment 4 , where 400 mbar vacuum was applied at both inlet and vent during post-filling.

dimensions of the brake material may allow for a better level of control of final part quality. By designing the resin system to gel at a desired time, it may be possible to choose the volume fraction of the final part, while insuring a minimum gradient of thickness along the laminate. However, this approach relies on resin pressures being reduced to the desired level during a slow post-filling phase and will be subject to several sources of variability. A combination of the application of a brake and the change of post-filling pressure at both inlet and vent is the approach recommended by the authors. The break ensures better impregnation of complex preforms and a more uniform compaction history, while turning the inlet into a vent allows for rapid reduction of the resin pressure inside the laminate to the desired level.

The closing of the inlet before completion of the filling did not help reducing the thickness gradient in the final part, the total cycle time was not reduced either. However, this technique allowed for a saving of around $10 \%$ in the quantity of fluid used. This could therefore offer significant savings in material cost, but the risk of having an incompletely impregnated part or a higher porosity may negate this benefit. 

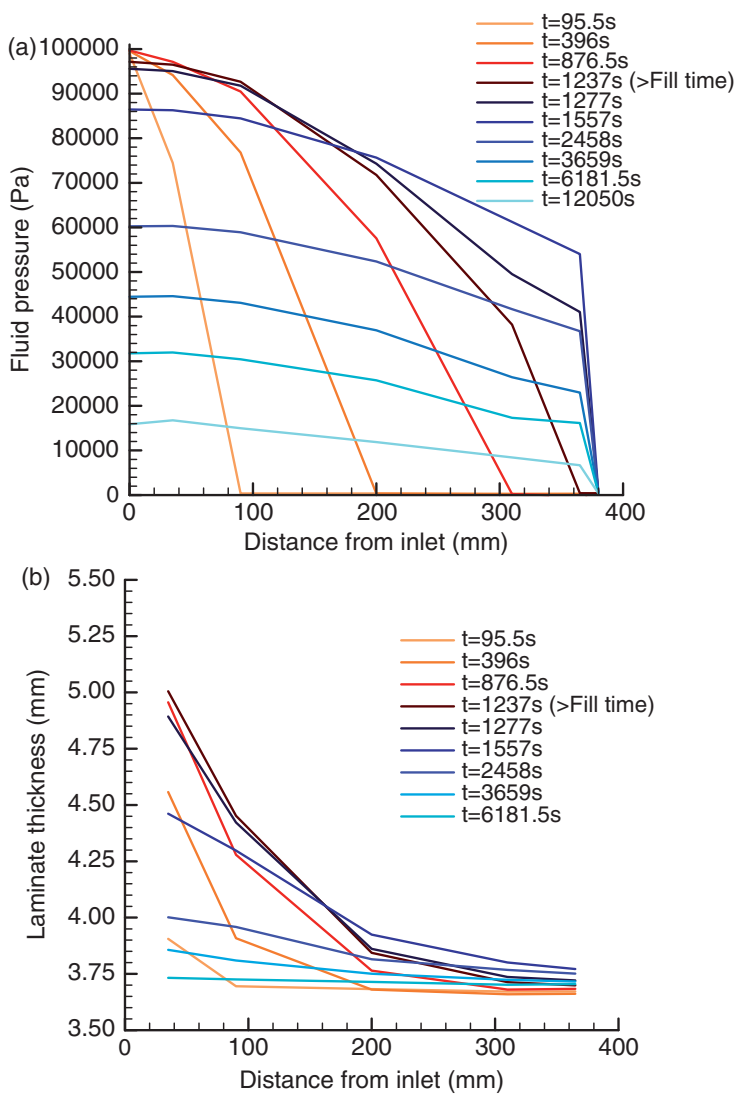

Figure 15. Pressure (a) and thickness (b) profiles at various instances during experiment 5 , where a break was placed between the preform and the vent.

This technique would also not be suitable to be used in conjunction with the application of vacuum at the inlet.

\section{Conclusion}

In this paper, the RI monitoring setup developed at the University of Auckland was used to evaluate the effect of several strategies applied during post-filling, considering evolution of laminate properties through to gelation of resin. Using a small mould and simple geometry, some guidelines have been proposed to improve productivity and reduce variability of component composition during manufacture of larger and more complex components. Turning the inlet into a vent proved very influential in the reduction of the time required for the post-filling stage and can greatly improve productivity. The control of the post-filling pressure showed potential for controlling the fibre volume fraction of the finished laminate, while at the same time limiting void generation due to the boiling off of resin. The use of a break between the preform and the vent, when used in conjunction with clamping the inlet proved to greatly increase the time required for post-filling, but it also permitted a much more homogeneous thickness of the laminate after post-filling. While clamping the inlet early can provide some cost savings by reducing the amount of resin needed, this technique does not create any time savings and may prove too risky for larger components.

The post-filling stage analysis carried out here is in its early stages and much work remains to be done in this area. The aim was to find the most critical parameters influencing the post-filling stage. A mineral oil was used as a test fluid for cost saving and ease of handling, but this eliminated the potential effect of the resin gelling and outgasing. Further study will be focused on the most promising parameters, evaluating their influence at various levels. Actual resin will be used instead of a test fluid to allow quality evaluation of the finished parts. The application of these various post-filling strategies, and the most prominent processing parameters should also be taken into account in the development of a RI simulation program covering the full length of the process, to help manufacturers better design their process without the need of expensive trial and error process development.

\section{Funding}

The authors would like to acknowledge the generous support of the Foundation for Research, Science and Technology, New Zealand.

\section{Acknowledgements}

We would also like to thank SP $\backslash$ High Modulus (NZ) and Aurora Glass Fibre (NZ) Ltd. for their support of this research.

\section{Conflict of interest}

None declared.

\section{References}

1. Bender D, Schuster J and Heider D. Flow rate control during vacuum-assisted resin transfer molding (VARTM) processing. Compos Sci Technol 2006; 66: 2265-2271.

2. Johnson RJ and Pitchumani R. Flow control using localized induction heating in a VARTM process. Compos $S c i$ Technol 2007; 67: 669-684.

3. Leonard-Williams S. The crossover from RTM to resin infusion. Reinf Plast 2008; 52: 28-29.

4. Grimsley BW, Hubert P, Song X, et al. Flow and compaction during the vacuum assisted resin transfer molding process. In: Proceedings of SAMPE Conference. Seattle, WA - November 5-8, 2001.

5. Tackitt $\mathrm{K}$ and Walsh S. Experimental study of thickness gradient formation in the vartm process. Mater Manuf Process 2005; 20: 607-627. 
6. Govignon Q, Allen T, Bickerton S, et al. Monitoring variations in laminate properties through the complete resin infusion process. In: Proceedings of SAMPE: From Art to Science: Advancing Materials \& Process Engineering Conference, Cincinnati, OH, October 29November 1, 2007, CD-Rom, pp.18.

7. Govignon Q, Bickerton S, Morris J, et al. Full field monitoring of the resin flow and laminate properties during the resin infusion process. Composites Part A 2008; 39: $1412-1426$.

8. Li J, Zhang C, Liang R, et al. Modeling and analysis of thickness gradient and variations in vacuum-assisted resin transfer molding process. Polym Compos 2008; 29: 473-482.

9. Yenilmez B, Senan M and Murat Sozer E. Variation of part thickness and compaction pressure in vacuum infusion process. Compos Sci Technol 2008; 69: 1710-1719.

10. Niggemann C, Young Seok S, Gillespie JW, et al. Experimental investigation of the controlled atmospheric pressure resin infusion (CAPRI) process. J Compos Mater 2008; 42: 1049-1061.

11. Li W, Krehl J, Gillespie JW Jr, et al. Process and performance evaluation of the vacuum-assisted process. J Compos Mater 2004; 38: 1803-1814.

12. Alms JB, Advani SG and Glancey JL. Liquid composite molding control methodologies using vacuum induced preform relaxation. Composites Part A 2011; 42: 57-65.

13. Alms JB, Glancey JL and Advani SG. Mechanical properties of composite structures fabricated with the vacuum induced preform relaxation process. Compos Struct 2010; 92: 2811-2816.

14. Govignon Q, Bickerton S and Kelly PA. Simulation of the reinforcement compaction and resin flow during the complete resin infusion process. Composites Part A 2010; 41: 45-57.

15. Robinson MJ and Kosmatka JB. Resin bleeding simulation for the VARTM process. In: Proceedings of SAMPE 2008 Conference, Long Beach, CA.

16. Simacek $\mathrm{P}$ and Advani SG. Modeling resin flow and fiber tow saturation induced by distribution media collapse in VARTM. Compos Sci Technol 2007; 67: 2757-2769.

17. Simacek P, Heider D, Gillespie JW Jr, et al. Post-filling flow in vacuum assisted resin transfer molding processes: theoretical analysis. Composites Part A 2009; 40: 913-924.

18. Technology update: Vacuum infusion. Reinf Plast 2004; 48: $28-29$.

19. Govignon Q, Bickerton S, Morris J, et al. A stereo photography system for monitoring full field thickness variation during resin infusion. In: Proceedings of FPCM8 Conference, Douais, France, July 2006, pp.231-239.

20. Terzaghi K. Theoretical soil mechanics. New York: John Wiley and Sons, 1943.

21. Somashekar AA, Bickerton S and Bhattacharyya D. Exploring the non-elastic compression deformation of dry glass fibre reinforcements. Compos Sci Technol 2007; 67: 183-200.

22. Chen B and Chou T-W. Compaction of woven-fabric preforms: nesting and multi-layer deformation. Compos Sci Technol 2000; 60: 2223-2231.

23. Skordos AA and Sutcliffe MPF. Stochastic simulation of woven composites forming. Compos Sci Technol 2008; 68: 283-296.

24. Gan JM, Bickerton S and Battley M. Automated characterisation of variability in glass fibre reinforcement architecture. In: Proceedings of 10th International Conference on Textile Composites Conference, Lille, France, pp.148-156, October 26-28, 2010, Lille France.

25. Bickerton S, Gan JM, Zhang F, et al. An optically based inverse method to measure in-plane permeability fields. In: Proceedings of 10th International Conference of Flow Processes in Composite Materials Conference, Monte Verita, Switzerland, July 11th-15th, 2010.

26. Bickerton S, Comas-Cardona S, Razali I, et al. Spatial compaction and saturated permeability variations of fibre reinforcements, In: Proceedings of 9th International Conference on Flow Processes in Composite Materials (FPCM9) Conference, Montreal, Quebec, Canada, July 8-10, 2008.

27. Govignon Q, Bickerton S and Kelly PA. Simulation of the complete resin infusion process, In: Proceedings of 9 th International Conference on Flow Processes in Composite Materials (FPCM9) Conference, Montreal, Quebec, Canada, July 8-10, 2008.

28. Daval B and Bickerton S. Exploring the potential for laminate quality control using VARTM. In: Proceedings of 36th International SAMPE Technical Conference, San Diego, CA, 15-18 November 2004.

29. Buntain MJ and Bickerton S. Compression flow permeability measurement: a continuous technique. Composites Part A 2003; 34: 445-457.

30. Govignon Q, Bickerton S and Kelly PA. Simulation of the reinforcement compaction and resin flow during the complete resin infusion process. Composites Part A 2010; 41: 45-57.

31. Umer R, Bickerton S and Fernyhough A. Characterising wood fibre mats as reinforcements for liquid composite moulding processes. Composites Part A 2007; 38: 434-448.

32. Loos AC and Springer GS. Curing of epoxy matrix composites. J Compos Mater 1983; 17: 135-169.

33. Wood JR and Bader MG. Void control for polymermatrix composites (1): theoretical and experimental methods for determining the growth and collapse of gas bubbles. Compos Manuf 1994; 5: 139-147.

34. Ledru Y, Bernhart G, Piquet R, et al. Coupled viscomechanical and diffusion void growth modelling during composite curing. Compos Sci Technol 2010; 70: 2139-2145.

35. Park CH, Lebel A, Saouab A, et al. Modeling and simulation of voids and saturation in liquid composite molding processes. Composites Part A 2011; 42: 658-668. 